\title{
DIVERSIDADE DE ESTRATÉGIAS PRODUTIVAS EM ECONOMIAS PRIVADAS E COLETIVAS NA AMAZÔNIA
}

\section{DIVERSITY OF PRODUCTIVE STRATEGIES IN PRIVATE AND COLLECTIVE ECONOMIES IN THE AMAZON}

\author{
Timni Vieira ${ }^{1}$ \\ Camila de Cássia do Socorro da Silva ${ }^{2}$ \\ Thayana Cristina de Andrade Rodrigues ${ }^{3}$ \\ Círia Cristiane da Rosa ${ }^{4}$ \\ Roberto Porro ${ }^{5}$ \\ Rodrigo Geroni Mendes Nascimento ${ }^{6}$
}

\begin{abstract}
RESUMO
Esta pesquisa teve como objetivo analisar a diferença entre estratégias familiares do uso do solo nas diferentes formas de propriedade da terra na Amazônia. A partir de uma pesquisa com 345 entrevistados em 15 municípios do Estado do Pará, os resultados apontaram uma maior diversificação nos arranjos coletivos com a combinação: "agricultura, capoeira e extrativismo florestal", evidenciando que não há diferença na diversidade produtiva quanto ao número total de espécies agrícolas cultivadas e no extrativismo das espécies florestais (sem diferenciação entre tipos de cultivo e dos usos florestais) entre os arranjos coletivos e particulares, assim como no tamanho médio da área de ocupação, com exceção do uso da cobertura florestal, utilizada para extrativismo, a qual demonstrou ser influenciada pela forma de propriedade da terra.
\end{abstract}

PALAVRAS-CHAVE: Uso e cobertura do solo. Uso comum na Amazônia. Campesinato amazônico.

\footnotetext{
${ }^{1}$ Doutoranda em Economia no Programa de Pós-graduação em Economia (PPGE) da Universidade Federal do Pará. E-mail: timni85vieira@gmail.com

2 Mestranda em Planejamento do Desenvolvimento no Programa de Pós-graduação em Desenvolvimento Sustentável do Trópico Úmido (PPGDSTU) do Núcleo de Altos Estudos Amazônicos da Universidade Federal do Pará. E-mail: camiladasssilva@gmail.com

3 Doutoranda em Planejamento do Desenvolvimento no Programa de Pós-graduação em Desenvolvimento Sustentável do Trópico Úmido (PPGDSTU) do Núcleo de Altos Estudos Amazônicos da Universidade Federal do Pará. E-mail: thayana23@gmail.com

4 Mestranda em Planejamento do Desenvolvimento no Programa de Pós-graduação em Desenvolvimento Sustentável do Trópico Úmido (PPGDSTU) do Núcleo de Altos Estudos Amazônicos da Universidade Federal do Pará. E-mail: ciriarosa1994@gmail.com

${ }^{5}$ Pesquisador da Embrapa Amazonia Oriental (Belém/PA). Docente permanente do Programa de PósGraduação em Agriculturas Amazônicas (PPGAA) do Instituto de Estudos da Agricultura Familiar da Universidade Federal do Pará. E-mail: roberto.porro@embrapa.br

${ }^{6}$ Docente no Programa de Pós-graduação em Ciências Florestais (PPGCF) da Universidade Federal Rural da Amazônia. E-mail: rodrigo.geroni@ufra.edu.br
} 


\section{ABSTRACT}

The objective of the research is to analyze if there is a difference between family land use strategies in the different forms of land ownership in the Amazon. The survey was conducted with 345 respondents in 15 municipalities in Pará and there was greater diversification in collective arrangements with the combination of "agriculture, 'capoeira' (altered soils by antropic action) and forestry for extractivism". There was no difference in productive diversity in total number of agricultural species cultivated and forest species (no differentiation between types of cultivation and forest use) between collective and private arrangements, as well as the average size of the area. There was only difference with the average size of the forest cover used for extractivism, which is influenced by the form of land ownership.

KEYWORDS: Land use; Collective land use management in Amazonia; Peasantry.

\section{INTRODUÇÃO}

A Amazônia abriga a principal floresta tropical do planeta. Possui uma diversidade não somente vegetal, mas de distintos arranjos sociais, por meio dos quais o território é manejado sob diversas formas, sejam estas coletivas em terras de uso comum, ou individual por famílias camponesas, agricultores e empresas rurais. Quanto às estratégias reprodutivas das famílias, estas são pautadas em questões que incluem, entre outras, a finalidade do uso da terra.

De maneira geral, as principais formas de uso do solo no meio rural na Amazônia são a agricultura, a pecuária e o extrativismo florestal. A tipologia de cobertura do solo resultante inclui cultivos agrícolas (anuais e perenes), pastagens, capoeiras e florestas. A destinação do uso e cobertura do solo atende aos interesses das unidades familiares de acordo com suas estratégias reprodutivas em arranjos individuais/privados ou coletivos/comuns, que priorizam a produção de alimentos, o extrativismo madeireiro e não madeireiro, a manutenção da vegetação e provisão de serviços ecossistêmicos, entre outras finalidades.

Assim sendo, este trabalho constituiu-se de pesquisa empírica realizada em 15 municípios do estado do Pará, a qual teve como objetivo analisar se as estratégias reprodutivas adotadas, a partir das formas de uso e cobertura do solo, diferenciam-se conforme a posse da terra seja individual ou coletiva.

\section{Formas de uso da terra na Amazônia: complexidade e diversidade}

A agricultura desde os tempos imemoriais faz parte da história e possui diferentes expressões no mundo todo, podendo ser abordada sob diversos paradigmas culturais, ecológicos, econômicos e sociais, entre outros (PENEREIRO, 2003). A terra passou a ser uma ferramenta de obtenção de conhecimentos para os seres humanos, os quais por meio da 
experimentação incorporaram técnicas, produziram instrumentos e aprimoraram tecnologias, que tornaram o sistema de manejo agrícola cada vez mais produtivo e eficiente (ANDRADE, 2019).

As principais atividades econômicas praticadas ao longo dos séculos por camponeses na Amazônia envolvem o uso da terra no manejo agrícola para roças e cultivos perenes, pastagens e a extração florestal dos produtos madeireiros ou não madeireiros (COSTA, 2020). No período da colonização portuguesa, a busca e a exploração das drogas do sertão por migrantes, fazendeiros pecuaristas e posseiros (MARTINS, 1981) foram o motivo de ocupação e redução da diversidade produtiva na Amazônia, pelo aumento da demanda por produtos como cacau, guaraná e castanha-do-Pará, dentre outros (COSTA, 2013). Transformações na diversidade dos sistemas produtivos e nas estratégias produtivas familiares locais na Amazônia foram também influenciadas pelos projetos de desenvolvimento que ocorreram a partir da década de 1960, quando incentivos do governo federal à agropecuária na região promoveram a implementação das atividades agrossilvipastoris (COSTA, 2013).

Pela proximidade semântica, os conceitos "cobertura do solo" e "uso da terra" são por vezes usados indistintamente, no entanto, o primeiro está diretamente associado ao revestimento, ou tipo de cobertura natural ou artificial (ROSA, 2007), enquanto o segundo refere-se à sua utilização cultural (NOVO, 2010).

Os estudos do uso da terra e da cobertura do solo são fundamentais para entender transformações na Amazônia, a partir da compreensão das ações antrópicas de caracterização e distribuição espacial dos tipos de vegetação natural que revestem o solo (ROSA, 2007). Sob este prisma, a diversidade se apresenta sob múltiplas formas de uso e ocupação relacionadas a cultivos agrícolas, capoeira, pastagem ou floresta. Essa diversidade é exemplificada pelo domínio da técnica da agricultura de corte e queima por indígenas, fundamental na formação das denominadas "Terras Pretas de Índio" (TPI), um solo rico em nutrientes orgânicos e propício ao desenvolvimento de vegetais (CLEMENT et al., 2009). Por outro lado, a agricultura de corte e queima torna-se insustentável na medida em que são feitas repetidas queimadas, o que reduz o tempo de pousio entre os cultivos (DENICH; KANASHIRO; VLEK, 1999).

Os povos camponeses desenvolveram técnicas agroecológicas empregadas no manejo da terra, a exemplo do pousio das roças e os policultivos, que segundo Denevan (2010) contribuíram na melhoria da qualidade do solo. A mandiocultura é exemplo de atividade 
agrícola que faz parte da diversidade produtiva que ocupa os solos amazônicos, a qual mesmo sendo cultivada de forma intensiva, é sucedida por espécies arbustivas após a colheita que acabam formando a capoeira (CLEMENT, 2001; CLEMENT et al., 2009), que pode tanto recompor um passivo ambiental quanto viabilizar o uso agrícola ou agropecuário em ciclos futuros pela recuperação da eficiência produtiva e características do solo, como um ativo ambiental (COSTA, 2004).

Na Amazônia, as crescentes áreas de pastagens degradadas resultantes da pecuária extensiva têm sido um problema crítico, exigindo cada vez mais técnicas de recuperação como a produção com incorporação dos componentes arbóreos, denominada silvipastoreio (DIASFILHO, 2006). A este conjunto de usos e ocupações dos solos amazônicos, cabe adicionar as florestas, cuja utilização é uma das principais características dos povos tradicionais da região (BRONDÍZIO, 2021). A elas estão associadas atividades relevantes como o extrativismo dos produtos florestais não-madeireiros (a exemplo das raízes, resinas, gomas, óleos, ceras, dentre outros) e madeireiros (madeira e lenha).

Por fim, para entender a riqueza dessa diversidade na Amazônia, cabe, primeiramente, entender os fundamentos dos sistemas produtivos das diversas categorias representadas pelas diferentes trajetórias tecnológicas. As trajetórias tecnológicas são, de acordo com Dosi (2006) ${ }^{7}$, citado por Costa (2012a), um padrão usual das atividades que se baseiam nos paradigmas tecnológicos para resolução dos problemas produtivos e reprodutivos nas dimensões econômica, institucional e social, ou, nas palavras de Costa (2012a), “'trajetórias tecnológicas' são formas reais-concretas de realização de um paradigma". Este paradigma, para Dosi (citado por Costa, 2009) refere-se a "um modelo ou um padrão" da solução dos problemas tecnológicos que abrangem as diversidades da relação entre trabalho humano, objetivado por um modo de produção, e seu objeto último, a natureza.

\section{Trajetórias Tecnológicas de uso do Bioma como força produtiva no meio rural amazônico}

A partir da diversidade nas formas de uso e ocupação do solo e de arranjos sociais existentes na Amazônia, importa também compreender a diversidade estrutural, ou seja, analisar os diferentes sistemas de produção no campo social, econômico, político e ambiental.

\footnotetext{
${ }^{7}$ DOSI, G. Technological paradigms and technological trajectories. In: Revista Brasileira de Inovações, v.5, n.1, 2006. p. 22-23.
} 
No contexto da diversidade estrutural, Costa (2007) aponta que na região Norte existe uma combinação entre fundamentos do trabalho, do capital físico e do capital natural, associados nas formas de produção básica que convergem para dois tipos de sistemas produtivos: o camponês e o patronal.

Uma avaliação comparativa dos três últimos censos agropecuários no território amazônico (1995, 2006 e 2017), constatou que estes sistemas se estruturam sob diferentes formas. O sistema de produção patronal é caracterizado pelos estabelecimentos baseados em trabalho assalariado, que convergem para a produção especializada com intenso uso mecânico do solo, como um sistema de produção que se associa ao uso de capital físico, com pouco manejo e/ou uso intenso do capital natural (COSTA, 2009; 2021). As trajetórias patronais são divididas em quatro tipos. A trajetória patronal T4 é caracterizada pelo sistema produtivo que converge para a pecuária de corte; a trajetória T5 converge ao sistema de plantation e às culturas permanentes. A trajetória T6, é representada pela silvicultura (COSTA, 2009). Por fim, recentemente, houve a inclusão da trajetória T7, com vistas ao cultivo de grãos (soja, milho e outros) (COSTA, 2021). Uma característica comum a todas as trajetórias patronais é a homogeneização da paisagem, fator este que tem causado alto impacto na biodiversidade.

Por outro lado, na trajetória camponesa, a racionalidade entre o capital natural e o modo de produção mecânico-químico se inverte, pois há a predominância da força de trabalho familiar combinada com uma relação fundiária expressa em estabelecimentos rurais de pequena escala, que se associa ao uso do capital físico (mecânico-químico) e ao manejo do capital natural (formações florestais primárias e secundárias), compondo sistemas de produção bastante diversos com predominância dos sistemas agroflorestais que dispõem da alta diversidade de componentes e interações (COSTA, 2021). Importa ressaltar que esta trajetória apresenta divide-se em torno de três trajetórias (COSTA \& FERNANDES 2016). A T1 representa um tipo de agricultura relativamente especializada, porém, com sistemas diversificados, de modo que nela realiza-se a pecuária de corte e o plantio das culturas permanentes. $\mathrm{O}$ uso do solo é intensivo, porém com baixo impacto na biodiversidade, bem como na formação de dejetos. Por outro lado, a trajetória T3 é marcada pelo uso extensivo do solo e homogeneização da paisagem, característica que gera alto impacto na biodiversidade, além da intensa quantidade de dejetos devido ao predomínio da atividade agropecuária, contribuindo com a emissão dos gases poluentes. Somam-se a estas características, a queima da floresta para formação de plantações 
e pastagens, assim contribuindo com a expansão das áreas degradadas (COSTA, 2009). Para finalizar, a trajetória tecnológica T2 consiste na trajetória camponesa que mais se alinha ao desenvolvimento sustentável, pois é peculiar de sua produção o uso da diversidade natural disponível, causando baixo impacto na biodiversidade e na formação dos impactos poluidores (COSTA, 2009).

A evolução e sustentação inovadora das trajetórias camponesas são importantes no contexto da diversidade, pois seus sistemas de produção podem representar um caminho alternativo e a busca pela consolidação de uma nova base produtiva (COSTA \& FERNANDES, 2016).

\section{A delimitação privada e não-privada da posse da terra na Amazônia}

Dentre as formas de posse da terra que ocorrem na Amazônia estão as terras de uso comum e a propriedade privada. Segundo Costa e Ravena (2017), os regimes de propriedade nos territórios amazônicos podem ser classificados em áreas particulares delimitadas por cercas simbólicas, áreas comunais e áreas sob domínio do patrão, sendo a posse comum constituída pelo uso coletivo dos recursos naturais, mediado pelas regras e direitos construídos e respeitados pelos usuários.

Para Tonucci Filho (2019), o comum está voltado às práticas e relações de produção e reprodução coletivas e cooperativas, baseadas no compartilhamento dos recursos, as primeiras constituindo relações sociais, e as segundas, modos de produção. Por outro lado, a propriedade privada confere ao detentor os direitos de uso absoluto, exclusividade e alienação sobre o bem possuído, baseando-se no direito de expulsar, sancionado pelo Estado, sendo a terra uma "mercadoria fictícia", prevalecendo o direito individual sobre o direito comunal.

$\mathrm{Na}$ Amazônia há um claro contraste entre o caráter privatista da propriedade da terra e a forma de uso e ocupação do território pelos povos indígenas, comunidades quilombolas, agroextrativistas e demais comunidades tradicionais. Nessa região, um dos principais traços de formação social é a persistência das políticas elitistas, patrimonialistas, voltadas para a acumulação de capital, características estas que não são adequadas nem aplicáveis no contexto amazônico, onde as práticas culturais e de produção seguem um fluxo muitas vezes alinhado aos ciclos ecológicos (BENATTI, 2011). As comunidades tradicionais incluem pequenos agricultores rurais de base familiar, com uma economia fundamentada no agroextrativismo, 
organizados social e politicamente, com certo envolvimento com o mercado e a sociedade ampla, além de uma relação com a natureza que os integra ao território nos arranjos coletivos. As comunidades que ocupam ou reivindicam o uso de áreas de conservação como Reservas Extrativistas (RESEX) e Reservas de Desenvolvimento Sustentável (RDS), além dos Assentamentos Agroextrativistas e Quilombos, são alguns exemplos de populações tradicionais (BENATTI, 2018).

As Reservas Extrativistas foram definidas como uma categoria de Unidade de Conservação de Uso Sustentável, com objetivo de atender, de forma satisfatória, seringueiros e ambientalistas quando da criação da lei 9.985/2000, que trata do Sistema Nacional de Unidades de Conservação (CUNHA, 2010). Trata-se de uma forma de gestão comunitária e coletiva dos recursos naturais para se contrapor à concentração fundiária e ao aumento das propriedades individuais (ESTRELA, 2020). Sendo uma unidade de conservação de uso sustentável, é permitido seu uso pelas populações tradicionais para o extrativismo, agricultura de subsistência e criação de animais de pequeno porte, tendo como objetivo "proteger os meios de vida e a cultura dessas populações e assegurar o uso sustentável dos recursos naturais da unidade", com regime de uso e posse viabilizado por contrato (BRASIL, 2000, art. 18 e 23).

Reservas de Desenvolvimento Sustentável (RDS) objetivam, além da preservação da natureza, assegurar a reprodução e a melhoria da qualidade de vida da população, valorizar, conservar e aperfeiçoar o conhecimento e manejo tradicional do ambiente (BRASIL, 2000). Enquanto as RESEX foram pensadas a partir da integração das propostas de seringueiros e ambientalistas, as RDS partiram de conflitos entre pesquisadores e povos tradicionais quando da criação de uma Estação Ecológica no estado do Amazonas, que deu origem à primeira RDS do país (QUEIROZ, 2005).

Os Projetos de Assentamento têm sofrido com o desmatamento há algum tempo, sendo essencial a integração da agenda ambiental na pauta fundiária para que modalidades de assentamento sejam adequadas, entre outros fatores, ao ambiente florestal e ao modo de vida das populações quanto ao não parcelamento do solo. Os Projetos de Assentamento Agroextrativistas são uma dessas modalidades e têm como objetivo incentivar práticas de populações tradicionais assentadas, seja com extrativismo vegetal, animal, produção sustentável e turismo ecológico. Além do aspecto produtivo, a criação destas áreas visa 
conservar as características e os costumes da população residente (SILVA et al., 2017; COSTA \& PORRO, 2019).

As Comunidades Quilombolas têm a terra como seu elemento central, importante para o reforço da coesão e identidade das comunidades e preservação do modo de vida. Nessas comunidades predomina o uso comum da terra, no qual esta não é considerada mercadoria, mas o espaço físico em que as unidades familiares constroem seu universo social (SILVA, 2019). Dalosto et al., (2019) enfatizam a insegurança social desse grupo, pelo fato de que, em sua grande maioria, não detém a propriedade das terras que ocupam. O último levantamento do Instituto Nacional de Colonização e Reforma Agrária (INCRA), em 2018, apontou que existiam 1.715 processos abertos para reconhecimento e titulação de comunidades quilombolas no Brasil, dos quais 23 estão titulados no estado do Pará. Segundo Schönenberg (2020), apesar de ter direito à terra, a concretização desse direito normalmente não ocorre devido a falhas na aplicação de ações de Estado.

Já Monteiro, Vasconcelos \& Treccani (2019), afirmam que a propriedade quilombola é a única modalidade de reconhecimento dos territórios tradicionais que transfere definitivamente a área para o grupo, em caráter coletivo, inalienável e intransferível, garantindo maior segurança jurídica à comunidade em relação ao seu direito territorial quando titulado. Esta condição não é tão eficaz nos casos de RESEX e projetos de assentamentos coletivos, para os quais a concessão é feita em caráter precário às comunidades tradicionais, por meio da Concessão do Direito Real de Uso (CDRU), o que os torna mais suscetíveis a alterações legislativas e à interferência externa sobre seus territórios.

Para Benatti (2018), quanto aos aspectos jurídicos, as populações tradicionais podem ser consideradas posseiras quando não tiveram seus direitos à terra reconhecidos, ocupando terras públicas ou privadas sem consentimento de terceiros, não possuindo títulos legais que lhes garantam o domínio da terra que estão de posse. Da mesma forma, produtores rurais que não estão entre as populações tradicionais referenciadas também podem sofrer com a distribuição e posse de terras, como os camponeses.

A terra enquanto propriedade camponesa é uma forma de reprodução de trabalho e de vida, mais do que instrumento de uso capitalista para obtenção de lucro, mesmo assim, no contexto amazônico, a distribuição da posse da terra ocorre de modo desigual, limitando a área que poderia ser destinada à agricultura familiar (MARTINS, 1981; FEARNSIDE, 2020). A 
agricultura camponesa é uma forma de produção muito presente na região amazônica e caracteriza-se pela união entre os agentes produtores e consumidores na propriedade rural, de forma indistinta na aplicação do trabalho e apropriação do consumo. É reconhecida uma relação de subalternidade imposta pelos capitalistas aos camponeses no que tange ao acesso à terra por meio de sua apropriação, condição necessária para a obtenção de uma autonomia relativa que lhes garanta a subsistência e, por consequência, independência. Pela ótica marxista, essa subalternidade pode ocorrer tanto ao nível de circulação (relação de trocas entre setor agrícola e industrial) quanto de produção (forma como o capital "desenha" o processo produtivo no campo para maior vantagem nas relações de trabalho) (ROMEIRO, 1992; COSTA, 2000; COSTA 2012b).

Considerando a complexidade dos arranjos de propriedade da terra que ocorrem na Amazônia e os diferentes usos do solo que competem na região, a indagação que guiou esta pesquisa é a seguinte: As estratégias de uso do solo, pelas unidades familiares, são influenciadas pelas diferentes formas de propriedade da terra na Amazônia?

\section{Formas de produção e propriedade da terra no rural amazônico}

A análise das formas de uso e cobertura do solo e as formas de propriedade na Amazônia foi realizada a partir dos dados coletados em pesquisa de campo por meio de entrevistas em 15 municípios no estado do Pará (Figura 1). Essa área foi delimitada a partir da base de dados obtida por meio do projeto SISLES (Sustainable Improvement of Swiddens for Livelihoods and Environmental Services) realizado em 2015 pela Embrapa Amazônia Oriental, em levantamento em campo de informações econômicas, sociais e ambientais sobre sistemas de produção em comunidades de produtores rurais, com objetivo de implementar uma pesquisaação para identificação e avaliação da viabilidade de intensificação sustentável dos sistemas de roçados a partir da integração com árvores nas paisagens. A escolha dos municípios considerou como critérios uma área mínima municipal de 500 ha de mandioca colhidos (e extremos de produtividade), predominância da agricultura familiar e a ocorrência de Assentamentos de reforma agrária e/ou Territórios Quilombolas, totalizando 345 domicílios entrevistados. 
Figura 1. Municípios da área de estudo.

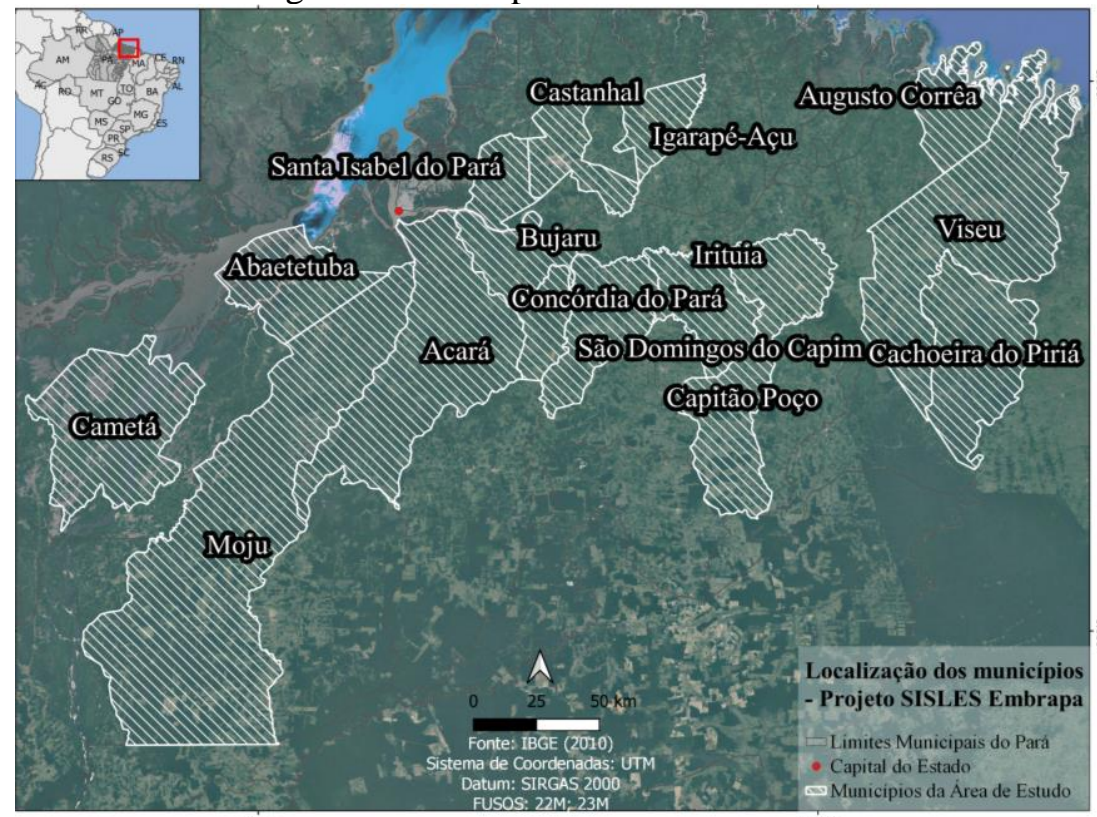

Fonte: os autores, adaptado de IBGE (2010).

Nestes municípios a maior parte da população é rural, em idade ativa (15-64 anos), com quase a totalidade dos estabelecimentos (99\%) sendo de agricultura familiar (IBGE, 2017). A produção agrícola (culturas temporárias e culturas permanentes) e florestal (extrativismo madeireiro e não madeireiro) predominam em volume produzido e área ocupada, além de pastagem (natural, plantada e silvipastoril) e capoeira (palhada, capoeira fina e capoeira grossa).

Nesta pesquisa foram identificadas sete categorias fundiárias: Projetos de Assentamento convencionais, Projetos de Assentamento Agroextrativistas, Unidades de Conservação de Uso Sustentável, Projetos de Colonização, Territórios Quilombolas, Propriedades Particulares Regularizadas e Terras Ocupadas sem Posse Regularizada. As similaridades entre essas categorias levaram ao agrupamento em três classes: i) Áreas de posse e de assentados (Projetos de Assentamento, Projetos Agroextrativistas, Projetos de Colonização e Terras Ocupadas sem Posse Regularizada), totalizando 159 domicílios entrevistados; ii) Territórios Tradicionais em Unidades de Conservação de Uso Sustentável e entorno (Territórios Quilombolas e Unidades de Conservação de Uso Sustentável), totalizando 75 domicílios; e iii) Propriedades Particulares Regularizadas, que aqui são em sua totalidade Camponesas, totalizando 111 domicílios entrevistados.

Os dados sobre número de espécies agrícolas cultivadas e espécies florestais extraídas foram contabilizados por unidade entrevistada, a partir da soma do número de espécies 
agrícolas diferentes cultivadas e soma do número de espécies florestais extraídas, sem distinguir entre agricultura permanente, temporária, extrativismo madeireiro e extrativismo não madeireiro. Estas somas, por entrevista, foram agrupadas nas três classes de forma de propriedade da terra. A análise foi feita a partir dos resultados obtidos no programa estatístico $\mathrm{R}^{\circledR}$ quando da interação entre as formas de propriedade e o uso agrícola ou florestal da terra, obtendo-se uma média fatorial de acordo com a combinação. Esta análise não considerou a cobertura da terra com Capoeira e Pastagem, sendo que nesta última ocorria somente uma espécie em cada. Vale ressaltar que não foram contabilizadas as espécies medicinais, condimentares, de fruteiras e hortaliças cultivadas em quintais agroflorestais ou hortas domésticas, o que pode ter influenciado os resultados comparativos.

O cálculo do número de espécies cultivadas por forma de propriedade da terra apresentou semelhança significativa entre as três classes analisadas. Isso significa que, a um nível de confiança de 5\%, a quantidade de espécies agrícolas cultivadas não é influenciada pela forma de propriedade da terra. Em média, Áreas de posse e de assentados cultivam quatro espécies agrícolas, enquanto os Territórios Tradicionais em Unidades de Conservação de Uso Sustentável e entorno e as Propriedades Particulares Camponesas cultivam cinco diferentes espécies. Essa condição se deu pela variabilidade dos dados dentro de cada forma de propriedade, havendo quantidades mínimas e máximas em cada classe que sobrepunham os limites das classes adjacentes. O extrativismo florestal também não apresentou diferença estatística entre a quantidade de produtos florestais extraídos das áreas de floresta nas diferentes classes de propriedade da terra, como apresentado na Tabela 1.

Tabela 1. Quantidade média (unidades) de espécies agrícolas cultivadas e espécies florestais extraídas por forma de propriedade da terra na área de estudo.

\begin{tabular}{|c|c|c|}
\hline Uso da terra & Forma de propriedade & Quantidade média de produtos \\
\hline \multirow{3}{*}{ Agrícola } & Áreas de posse e de assentados & $4,47 \mathrm{a}$ \\
\hline & $\begin{array}{l}\text { Territórios Tradicionais em Unidades de } \\
\text { Conservação de Uso Sustentável e entorno }\end{array}$ & $4,59 \mathrm{a}$ \\
\hline & Propriedades Particulares Camponesas & $4,97 \mathrm{a}$ \\
\hline \multirow{3}{*}{$\begin{array}{l}\text { Extrativismo } \\
\text { florestal }\end{array}$} & Áreas de posse e de assentados & $2,20 \mathrm{a}$ \\
\hline & $\begin{array}{l}\text { Territórios Tradicionais em Unidades de } \\
\text { Conservação de Uso Sustentável e entorno }\end{array}$ & $2,04 \mathrm{a}$ \\
\hline & Propriedades Particulares Camponesas & $1,94 \mathrm{a}$ \\
\hline
\end{tabular}


*Médias seguidas por letras diferentes diferem estaticamente pelo Teste de Tukey a 5\%.

Contrariamente, ao analisar a comunidade quilombola Abacatal, no Pará, Araújo et al., (2017), verificaram ampla diversidade de usos e produtos da terra e afirmaram que ao se diversificar as atividades agrícolas na agricultura familiar, se amplia a quantidade de produtos comercializados e se garante o autoconsumo. Neste mesmo sentido, Moraes (2019), também verificou uma ampla diversidade de uso da terra, ao estudar a comunidade quilombola Baixinha, no estado do Pará, observando que os principais produtos explorados pela comunidade eram os produtos florestais não madeireiros (PFNM), produtos dos sistemas agroflorestais e plantações.

Já em estudo realizado por Teixeira et al. (2018) em Reservas Extrativistas terrestres na Amazônia, nos estados do Acre, Amapá, Amazonas, Pará e Rondônia, também encontrou uma diversidade produtiva nas unidades familiares entrevistadas, a maior parte das unidades familiares entrevistadas praticavam apenas uma atividade, com destaque para produtos agrícolas em mais de $50 \%$ dos entrevistados, além do extrativismo florestal, em cerca de 42,8\% destes.

Com relação à área ocupada, foram feitas duas análises na área de estudo. A primeira buscou verificar se havia diferença estatística no tamanho médio das áreas ocupadas com cada tipo de uso em cada forma de propriedade da terra. As áreas ocupadas por cultivos agrícolas, pastagem, capoeira e cobertura florestal para extrativismo foram agrupadas nas três classes de propriedade da terra, e então para cada uma das combinações foi calculada a média fatorial específica no programa estatístico $\mathrm{R}^{\circledR}$ e posteriormente a proporção destas combinações.

Antes de apresentar estes resultados, cabe ressaltar que a área com agricultura é a mais expressiva nas três formas de propriedade, seguido do extrativismo em florestas, usos que juntos respondem por aproximadamente $80 \%$ do total em Territórios Tradicionais em Unidades de Conservação de Uso Sustentável e entorno, assim como nas Áreas de posse e de assentados. Resultado semelhante foi encontrado por Guimarães (2013), que ao estudar as formas de uso da terra na Reserva de Desenvolvimento Sustentável do Uatumã, no estado do Amazonas, verificou que nessa Reserva existe um modelo tradicional de ocupação e uso da terra, sendo a agricultura, realizada no modelo familiar, a principal forma de uso da terra observada, seguida da pecuária, pesca e extrativismo. $\mathrm{O}$ autor observa que nessa RDS, tanto a agricultura quanto a pecuária apresentam baixo impacto, mas salienta que há grande variedade de espécies plantadas 
nas áreas agrícolas desta localidade, totalizando em torno de 34 culturas agrícolas, demonstrando expressiva diversidade, tanto de uso da terra, quanto de espécies cultivadas.

Considerando a área média destinada a cada uso e cobertura do solo, as médias encontradas para a agricultura, capoeira e pastagem não apresentaram diferença estatística nas diferentes formas de propriedade da terra, possivelmente pela variação entre as unidades familiares entrevistadas, a ponto de a estratificação em formas de propriedade não influenciar esta variável. A área de floresta, contudo, não teve esse comportamento, sendo então diferenciada entre os arranjos coletivos e particulares, ao nível de confiança de 5\%, conforme pode ser observado na Tabela 2.

Tabela 2. Área (ha) de uso e ocupação da terra pelos domicílios.

\begin{tabular}{lcccc}
\hline & Agrícola & Floresta & Pastagem & Capoeira \\
\hline Quilombolas & $3279.16 \mathrm{a}$ & $1258.14 \mathrm{a}$ & $1952.97 \mathrm{a}$ & $1807.48 \mathrm{a}$ \\
\hline Posseiros \& assentados & $3139.40 \mathrm{a}$ & $1473.81 \mathrm{~b}$ & $2088.39 \mathrm{a}$ & $1677.95 \mathrm{a}$ \\
\hline Particular & $3436.13 \mathrm{ab}$ & $1399.92 \mathrm{ab}$ & $2087.59 \mathrm{a}$ & $1736.84 \mathrm{a}$ \\
\hline
\end{tabular}

*Médias seguidas por letras diferentes diferem estaticamente pelo Teste de Tukey a 5\%.

Uma segunda análise na área de estudo verificou a diversidade de usos e cobertura do solo em cada classe de propriedade da terra, variando de um único até combinações variadas de usos e coberturas do solo (combinação entre agricultura, capoeira, pastagem e floresta). Para isso, os dados foram organizados, por unidade entrevistada, identificando-se a quantidade e as combinações e então agrupando-as nas três formas de propriedade. Assim, foram obtidas as áreas totais ocupadas desde um até o máximo de combinação, qual seja, "agricultura, capoeira, pastagem e floresta" em uma mesma unidade familiar, nas diferentes formas de propriedade da terra. Esses valores foram então calculados em termos de proporção da área total de toda a área de estudo.

Em número de unidades familiares entrevistadas, a agricultura é a atividade mais frequente, presente em 338 das 345 das unidades entrevistadas, seguido de capoeira em 253 unidades, cobertura florestal com uso extrativista em 125 unidades e pastagem em 67 unidades entrevistadas. Em mais de $80 \%$ destas unidades familiares o solo é parcelado entre diferentes atividades, com destaque para a combinação "agricultura e capoeira” (Figura 2). 
Figura 2. Representação esquemática das diferentes formas de uso de propriedade da terra na Amazônia.

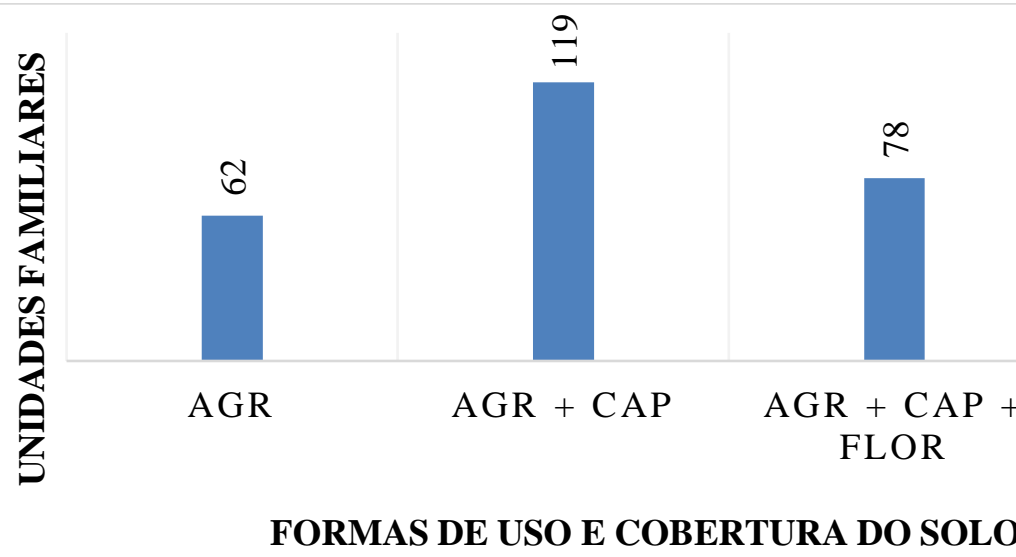

Fonte: Elaboração dos autores.

Em termos de área, no entanto, o espaço ocupado com três usos foi de mais de 55\% do total entrevistado, enquanto a soma das áreas com dois usos respondeu por aproximadamente $34 \%$. Observou-se que quando se incorpora a floresta no uso múltiplo da área, as unidades familiares entrevistadas em arranjos coletivos se sobrepõem àquelas com arranjos familiares particulares.

A manutenção da floresta em função do uso coletivo de produtores rurais também foi observada por Brondízio et al. (2009) em pesquisa realizada em Santarém, Pará, onde os pequenos produtores têm conseguido manter uma parte da floresta primária em suas terras. Os autores demonstram pequenos produtores mantêm $85 \%$ de suas terras com floresta, enquanto os grandes produtores mantiveram 70,7 \%. Guimarães (2013), ao estudar as formas de uso da terra na RDS do Uatumã, no estado do Amazonas, verificou que nessa Reserva, existe um modelo tradicional de ocupação e uso da terra pelas famílias, sendo a agricultura a principal forma de uso da terra seguida da pecuária, pesca e extrativismo.

A destinação da área para usos múltiplos pelos domicílios também foi uma realidade encontrada nas comunidades quilombolas de Abacatal por Araújo et al., (2017), e Baixinha, por Moraes (2019), ambas no Pará. Nas duas comunidades há uma interação dinâmica entre várias atividades agrícolas, que incluem desde o cultivo de roças, de sistemas agroflorestais, quintais agroflorestais, extrativismo, dentre outras atividades, utilizando para isso mão de obra familiar. Realidade similar foi encontrada também por Soares et al. $(2018$,$) ao investigarem a$ produção de alimentos destinados ao autoconsumo e o extrativismo de látex, no assentamento 
Seringal, na Amazônia Meridional. Os autores verificaram que além da extração de látex, a maioria das unidades produtivas familiares $(91 \%)$ produzia de três a quatro culturas, destinadas para a comercialização do excedente, e de seis a 12 culturas voltadas exclusivamente à alimentação familiar, sendo que a motivação para a produção para autoconsumo ocorre pela redução de despesas com compra de alimentos e a disponibilidade destes em quantidade e qualidade, garantindo a "segurança alimentar" dessas famílias, demonstrando que a produção de alimentos é uma importante estratégia para a permanência das famílias no campo.

\section{CONSIDERAÇÕES FINAIS}

A análise dos dados coletados nesta pesquisa permite afirmar que dentre as quatro principais formas de uso e cobertura do solo na Amazônia, agricultura, capoeira, pastagem e floresta, a agricultura foi o uso mais frequente, seguido da capoeira, floresta e pastagem. A diversidade produtiva não foi influenciada pelas formas de propriedade, ou seja, a quantidade das espécies cultivadas na agricultura e extraídas nas florestas não é influenciada pelo uso comunitário ou individual da área. Esta condição, contudo, pode ser alterada se os dados forem submetidos a uma análise dos subgrupos do uso da terra, como agricultura anual, agricultura permanente, extrativismo dos produtos florestais madeireiros e não madeireiros.

Em relação ao parcelamento do solo com diferentes atividades produtivas, nesta pesquisa observou-se que mais da metade da área avaliada era ocupada pelas unidades familiares que utilizam o solo com três diferentes atividades, sendo que na amostra, o componente "floresta" é mais frequente em usos múltiplos do solo em arranjos coletivos de unidades familiares.

Quanto ao tamanho médio da área ocupada, observou-se por meio das estatísticas que a cobertura do solo pela agricultura, pastagem e capoeira não apresentou diferenças quanto às formas de propriedade da terra, o que pode ser reconsiderado se fossem analisadas as classes das áreas de uso da terra, além dos outros subgrupos. Quanto à pastagem e a capoeira, em uma análise considerando pastos plantados, naturais e integrados com floresta, além das capoeiras nos diferentes estágios de recuperação da vegetação, pode-se demonstrar um comportamento variado pelas categorias de propriedade da terra. O tamanho médio da área da floresta para extrativismo, por sua vez, apresentou-se diferente e influenciado pela forma de propriedade particular ou não particular. 


\section{REFERÊNCIAS BIBLIOGRÁFICAS}

ANDRADE, Dayana Velozo Pastor. Agricultura, Meio Ambiente e Sociedade: um estudo sobre a adotabilidade da agricultura sintrópica. 2019. 160 f. Dissertação (Mestrado em Ciências Ambientais e Conservação), Universidade Federal do Rio de Janeiro, 2019. Disponívelem: <http://ppgciac.macae.ufrj.br/images/Disserta\%C3\%A7\%C3\%B5es/DAYANA _VELOZO_PASTOR_ANDRADE.pdf >. Acesso em 15 nov. 2021.

ARAÚJO, Allyne dos Santos et al. Análise socioeconômica de agricultores da comunidade quilombola do Abacatal, Ananindeua, estado do Pará, Brasil. Biota Amazônia, Macapá, v. 7, n. $1, \quad$ p. 30-37, 2017.2 Disponível em: <https://periodicos.unifap.br/index.php/biota/article/view/2466/v7n1p30-37.pdf>. Acesso em 06 nov. 2021.

BENATTI, José Heder. Das Terras Tradicionalmente Ocupadas ao Reconhecimento da Diversidade Social e de Posse das Populações Tradicionais na Amazônia. In: UNGARETTI, Débora; LESSA, Marília Rolemberg; COUTINHO, Diogo R.; PROL, Flávio Marques; MIOLA; Iagê Zendron; FERRANDO, Tomaso. (Ed). Propriedades em Transformação: Abordagens Multidisciplinares sobre a Propriedade no Brasil, p. 195-216, 2018. Disponível em: <https://openaccess.blucher.com.br/article-list/9788580393279-397/list\#undefined>. Acesso em 08 nov. 2021.

BENATTI, José Heder. Propriedade comum na Amazônia: acesso e uso de recursos naturais pelas populações tradicionais. In: SAUER, Sérgio; ALMEIDA, Wellington (Orgs.). Terras e territórios na Amazônia: demandas, desafios e perspectivas. Brasília: Universidade de Brasília, 2011. p. 93-113. Disponível em: <https://www.researchgate.net/publication/281562869_Propriedade_comum_na_Amazonia_a cesso_e_uso_dos_recursos_naturais_pelas_populacoes_tradicionais $>$. Acesso em 08 nov. 2021.

BRASIL. Lei $\mathrm{n}^{\circ}$ 9.985, de 18 de julho de 2000. Regulamenta o art. 225, ... Institui o Sistema Nacional de Unidades de Conservação da natureza e dá outras providências. Diário Oficial [da] República Federativa do Brasil. Brasília, DF, 19 jul. 2000. Disponível em: < http://www.planalto.gov.br/ccivil_03/leis/19985.htm>. Acesso em: 05 jan. 2022.

BRONDÍZIO, Eduardo Sonnewend; CAK, Anthony; CALDAS, Marcellus Marques; MENA, Carlos; BILSBORROW, Richard; FUTEMMA, Celia; LUDEWIGS, Thomas; MORAN, Emilio Frederico; BATISTELLA, Mateus. Pequenos Produtores e o Desmatamento na Amazônia. Amazonia and Global Change: Geophysical Monograph Series, v. 186, 2009. Disponívelem: <https://daac.ornl.gov/LBA/lbaconferencia/amazonia_global_change/8_Peque nos_Produtores_Brondizio.pdf $>$. Acesso em 10 nov. 2021. 
BRONDÍZIO, Eduardo Sonnewend. Uma agricultura amazônica: sem o conhecimento do agricultor ribeirinho não haveria expansão global da economia do açaí. In: CUNHA, Manuela Carneiro da; MAGALHÃES, Sônia Barbosa; ADAMS, Cristina. (Org.).; EMPERAIRE, Laure, coordenadora da seção 7. Povos Tradicionais e Biodiversidade no Brasil: Contribuições dos povos indígenas, quilombolas e comunidades tradicionais para a biodiversidade, políticas e ameaças. São Paulo: SBPC, 2021. 351 p. Disponível em: <http://portal.sbpcnet.org.br/livro/povostradicionais7.pdf>. Acesso em 11 nov. 2021.

CLEMENT, Charles Roland; KLÜPPEL, Marina Pinheiro; GERMAN, Laura; ALMEIDA, Samuel Soares de; MAJOR, Julie; ARAGÃO, Luiz Eduardo Oliveira e Cruz de; GUIX, Juan Carlos, LLERAS, Eduardo; WINKLERPRINS, Antoinette M. G. A.; HECHT, SUSANNA B.; MCCANN, Joseph. A Diversidade Vegetal em Solos Antrópicos da Amazônia. In: TEIXEIRA, Wenceslau Geraldes; KERN, Dirse Clara; WOODS, William; LIMA, Hedinaldo Narciso; MADARI, Beata Emöke (org.). As Terras Pretas de Índio da Amazônia: Sua Caracterização e Uso deste Conhecimento na Criação de Novas Áreas. Manaus: Embrapa Amazônia Ocidental,

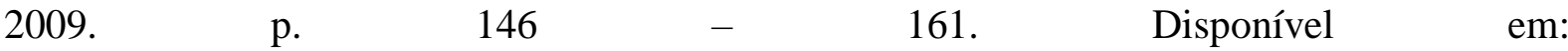
<https://www.alice.cnptia.embrapa.br/alice/handle/doc/684554>. Acesso em 10 nov. 2021.

CLEMENT, Charles Roland. Melhoramento de espécies nativas. In: NASS, Luciano Lourenço; VALOIS, Afonso Celso Candeira; MELO, Itamar Soares de; VALADARESINGLIS, Maria Cléria (Eds.). Recursos genéticos \& melhoramento - plantas. Fundação de Apoio à Pesquisa Agropecuária de Mato Grosso. Rondonópolis: Fundação MT, 2001. p. 423 441. Disponível em: <https://silo.tips/download/melhoramento-de-especies-nativas-institutonacional-de-pesquisas-da-amazonia-inp>. Acesso em 13 nov. 2021.

COSTA, Francisco de Assis. PATH dependency e a transformação agrária do bioma amazônico: o sentido econômico das capoeiras para o desenvolvimento sustentável. Novos Cadernos NAEA, v. 7 , n. 2, p. 111-158, dez. 2004. Disponível em: <http://repositorio.ufpa.br/jspui/bitstream/2011/3170/1/Artigo_PathDependencyTransformaca o.pdf>. Acesso em 11 nov. 2021.

COSTA, Francisco de Assis. Trajetórias Tecnológicas como Objeto de Política de Conhecimento para a Amazônia: uma metodologia de delineamento. Revista Brasileira de Inovação, Campinas, SP, v. 8, n. 1, p. 35-86, 2009. Disponível em: <https://periodicos.sbu.unicamp.br/ojs/index.php/rbi/article/view/8648975>. Acesso em: 11 nov. 2021.

COSTA, Francisco de Assis. Economia camponesa nas fronteiras do capitalismo: teoria e prática nos EUA e na Amazônia Brasileira. Belém: NAEA, 2012a. 310 p.

COSTA, Francisco de Assis. A. Formação agropecuária da Amazônia: os desafios do desenvolvimento sustentável. Belém: NAEA, 2012b. 299 p. 
COSTA, Francisco de Assis. Ecologismo e questão agrária na Amazônia. 2. Ed. Belém: NAEA, 2013. 86 p.

COSTA, Francisco de Assis. Economia camponesa referida ao bioma da Amazônia: atores, territórios e atributos. Paper do NAEA. V.20. n.2. p. 146 - 167, 2020. Disponível em: <https://periodicos.ufpa.br/index.php/pnaea/article/view/10390> Acesso em 08 nov. 2021.

COSTA, Francisco de Assis. Mudança estrutural na economia agrária da Amazônia: uma avaliação inicial usando os censos agropecuários (1995, 2006 e 2017). Boletim Regional, urbano e ambiental, n. 23, Edição Especial Agricultura 2020 - IPEA, 2020. Disponível em: $<$ http://repositorio.ipea.gov.br/bitstream/11058/10480/1/brua_23_artigo6.pdf >. Acesso em 08 nov. 2021.

COSTA, F. A.; FERNANDES, Danilo Araújo. Dinâmica Agrária, Instituições e Governança Territorial para o Desenvolvimento Sustentável da Amazônia. Revista de Economia Contemporânea (Impresso), v. 20, p. 517-552, 2016. Disponível em: <https://www.scielo.br/j/rec/a/spyfJ4ZsdFHGtQDJWMmHfNf/abstract/?lang=pt > Acesso em 05 nov. 2021.

COSTA, Francimara Souza da; RAVENA, Nirvia. Territórios e cercas simbólicas em regimes de propriedades comuns na Amazônia. Geosul, v. 32, n. 63, p. 159-179, 2017. Disponível em: <https://periodicos.ufsc.br/index.php/geosul/article/view/2177-5230.2017v32n63p159>. Acesso em 10 nov. 2021.

COSTA, Mara Cristina de Lima; PORRO, Roberto. Assentamentos convencionais e projetos de desenvolvimento sustentável em Anapu, Pará: percepções locais da trajetória de implementação. Revista Retratos de Assentamentos, v. 22, n. 2, p. 63-98, 2019. Disponível em: <https://retratosdeassentamentos.com/index.php/retratos/article/view/376/304>. Acesso em 06 jan. 2022.

CUNHA, Cláudia Conceição. Reservas Extrativistas: institucionalização e implementação no estado brasileiro dos anos 1990. 2010. 308 f. Tese (Doutorado em Psicossociologia de Comunidades e Ecologia Social), Universidade Federal do Rio de Janeiro, 2010. Disponível em:<http://pos.eicos.psicologia.ufrj.br/wpcontent/uploads/2010_DOUT_Claudia_Conceic\%C C\%A7a\%CC\%83o_Cunha.pdf>. Acesso em 06 nov. 2021.

DALOSTO, Cássius Dunck; DALOSTO; João Augusto Dunck; OLIVEIRA, Celso Lucas Fernandes. As Políticas Públicas para as Comunidades Quilombolas no Brasil. In: LACERDA, Gustavo Biscaia de. (Org.) As políticas públicas frente a transformação da sociedade. Ponta Grossa, PR: Atena Editora, 2019. p. 155-166. Disponível em: $<$ https://www.atenaeditora.com.br/wp-content/uploads/2019/08/e-book-As-Politicas-Publicasfrente-a-Transformacao-da-Sociedade.pdf $>$. Acesso em 13 nov. 2021. 
DENICH, Manfred; KANASHIRO, Milton; VLEK, Paul L. G. The potential and dynamics of carbon sequestration in traditional and modified fallow systems of the Eastern Amazon region, Brazil. In: LAL, Rattan; KIMBLE, J. M.; STEWART, B. A. (Ed.) Global climate change and tropical ecosystems. Boca Raton: CRC, 1999. p. 213-229. Disponível em: <https://bityli.com/nmzbo>. Acesso em 13 nov. 2021.

DENEVAN, William M. Machados de pedra versus machados de metal: a ambiguidade da agricultura de coivara na Amazônia pré-histórica. Revista Amazônica de Antropologia. V.2. n.2. $\quad$ p. $314 \quad-\quad 326, \quad 2010 . \quad$ Disponível em: <https://periodicos.ufpa.br/index.php/amazonica/article/view/403/836>. Acesso em 13 nov. 2021.

DIAS-FILHO, Moacyr Bernardino. Sistemas Silvipastoris na Recuperação de Pastagens Degradadas. Documentos, n. 258. Belém, PA: Embrapa Amazônia Oriental, 2006. 34p. Disponível em: <https://www.infoteca.cnptia.embrapa.br/bitstream/doc/409785/1/Doc258.pdf>. Acesso em 12 nov. 2021.

ESTRELA, Lilian Mércia Benevenuto. Populações Tradicionais e Reservas Extrativistas: Para quem habita esses territórios protegidos, quais fatores emergem como essenciais ao bemestar e qualidade de vida? 2020. 181 f. Dissertação (Mestrado Profissional em Biodiversidade em Unidades de Conservação), Instituto de Pesquisas Jardim Botânico do Rio de Janeiro, 2020. Disponível

em: $<$ https://ava.icmbio.gov.br/mod/data/view.php?d=17\&mode=single\&page=26>. Acesso em 13 nov. 2021.

FEARNSIDE, Philip Martin. Questões de posse da terra como fatores na destruição ambiental na Amazônia brasileira: O caso do sul do Pará. p. 39-54. In: Fearnside, Philip Martin. (ed.). Destruição e Conservação da Floresta Amazônica, Vol. 1. Editora do INPA, Manaus. 368 p. 2020. Disponível em: <https://bityl.co/6qHu>. Acesso em 22 nov. 2021.

GUIMARÃES, Eduardo Rizzo. Caracterização e diagnóstico do uso da terra na Reserva de Desenvolvimento Sustentável de Uatumã, AM. Instituto Nacional de Pesquisas da Amazônia (INPA). Programa de Pós-Graduação em Gestão de Áreas Protegidas na Amazônia Dissertação (mestrado), Manaus, 2013. Disponível em: <https://bdtd.inpa.gov.br/handle/tede/1075>. Acesso em 18 nov. 2021.

IBGE - Instituto Brasileiro de Geografia e Estatística. Censo Demográfico: séries temporais. 2010. Tabela 202. Disponível em: <https://sidra.ibge.gov.br/tabela/202>. Acesso em 21 ago. 2021. 
IBGE - Instituto Brasileiro de Geografia e Estatística. Censo Agropecuário 2017. Tabela 6884. 2017. Disponível em: <https://sidra.ibge.gov.br/tabela/6884>. Acesso em 30 ago. 2021.

INCRA - Instituto Nacional de Colonização e Reforma Agrária. Certificação. Disponível em: <https://certificacao.incra.gov.br/csv_shp/export_shp.py>. Acesso em 09 ago. 2021.

INCRA - Instituto Nacional de Colonização e Reforma Agrária. Coordenação Geral de Regularização de Territórios Quilombolas - DFQ: Processos abertos. Disponível em: <https://antigo.incra.gov.br/media/docs/quilombolas/processos_abertos.pdf>. Acesso em 05 jan. 2022.

MARTINS, José de Souza. Os camponeses e a política no Brasil. As lutas sociais no campo e seu lugar no processo político. Petrópolis: Vozes, 1981. Disponível em: $<$ https://felipemaiasilva.files.wordpress.com/2016/03/souza-martins-jose-de-os-camponesese-a-politica-no-brasil.pdf $>$. Acesso em 15 nov. 2021.

MONTEIRO, Aianny Naiara Gomes; VASCONCELOS, Tatiane Rodrigues de; TRECCANI, Girolamo Domenico. Impasses e desafios da regularização fundiária para comunidades tradicionais na Amazônia. Retratos De Assentamentos, 22(2), 39-62. 2019. Disponível em: $<$ https://retratosdeassentamentos.com/index.php/retratos/article/view/385>. Acesso em 13 nov. 2021.

MORAES, Carla Kelen de Andrade; DE CARVALHO, João Olegário Pereira; DOS SANTOS, André Sousa. A relação entre comunidade e floresta: um estudo de caso da comunidade quilombola Baixinha, Baião/PA. Cadernos CEPEC, v. 6, n. 7-12, 2019. Disponível em: <https://periodicos.ufpa.br/index.php/cepec/article/view/7039>. Acesso em: 15 nov. 2021.

NOVO, Evelyn Márcia Leão de Moraes. Sensoriamento Remoto: Princípios e Aplicações. $4^{\mathrm{a}}$ ed. São Paulo: Edgard Blücher, 2010. 308 p. Disponível em: <https://bityli.com/oSLIN>. Acesso em 08 nov. 2021.

QUEIROZ, Helder. A reserva de desenvolvimento sustentável Mamirauá. Estudos Avançados v. $19, \quad$ n. $54, \quad$ p. 183-203. 2005. Disponível em: <https://www.scielo.br/j/ea/a/xtLyDBxZyng85RYByJMGtmC/?lang=pt>. Acesso em 05 jan. 2022.

PENEREIRO, Fabiana Mongeli. Fundamentos da agrofloresta sucessional. In: SIMPÓSIO DE AGROFLORESTA SUCESSIONAL, 02, 2003. Aracaju. Anais [...] Sergipe: 2003. Disponível em:

<http://tctp.cpatu.embrapa.br/bibliografia/4_agrofloresta_sucessional_sergipe_peneireiro.pdf >. Acesso: 07 jan. 2022.

ROSA, R. Introdução ao sensoriamento remoto. Uberlândia: Ed. UFU, 2007. 
ROMEIRO, Ademar Ribeiro. Progresso técnico, organização da produção e condições de trabalho na agricultura. Revista Brasileira de Economia, v. 46, n.3. p. 377-397. 1992. Disponível em: <https://bibliotecadigital.fgv.br/ojs/index.php/rbe/article/view/2645>. Acesso em: 16 dez. 2021.

SCHÖNENBERG, Regine. How to overcome the development deadlock in the Quilombo Vila Formosa, Brazil? Journal of Land Use Science, v. 15, n. 2-3, p. 406-423, 2020. Disponível em: <https://www.researchgate.net/publication/340433410_How_to_overcome_the_developm ent_deadlock_in_the_Quilombo_Vila_Formosa_Brazil>.Acesso em: 21 nov. 2021.

SILVA, Valdecy dos Anjos da et al. Assentamento Agroextrativista e a dinâmica de Desenvolvimento na Amazônia: um estudo de caso da comunidade São Braz no PAE Eixo Forte em Santarém/PA. In: SEMINÁRIO INTERNACIONAL SOBRE DESENVOLVIMENTO REGIONAL, 8, 2017, Santa Cruz do Sul - RS. Anais... Santa Cruz do Sul: $\quad$ UNISC, $2017 . \quad$ Disponível em: <https://online.unisc.br/acadnet/anais/index.php/sidr/article/view/ 16668/4213>. Acesso em 06 jan. 2022.

SILVA, Jean Michel Moreira da. Uso comum ou propriedade privada? o processo de construção e regulamentação do artigo 68 do Ato das Disposições Constitucionais Transitórias. Universidade de Brasília (UnB) Instituto de Ciências Sociais (ICS) Programa de Pós-Graduação em Sociologia. Tese (doutorado), 2019. Disponível em: <https://repositorio.unb.br/handle/10482/38030>. Acesso em 18 nov. 2021.

SOARES, Keller Regina; FERREIRA, Esvanio Edipo da Silva; SEABRA JUNIOR, Santino; NEVES, Sandra Mara Alves da Silva. Extrativismo e Produção de Alimentos como Estratégia de Reprodução de Agricultores Familiares do Assentamento Seringal, Amazônia Meridional. Revista de Economia e Sociologia Rural, v. 56, p. 645-662, 2018. Disponível em: <https://www.scielo.br/j/resr/a/hKDnz3qkx6T4ycFLWkxzQYj/?lang=pt>. Acesso em 17 nov. 2021.

TEIXEIRA, Thaís Helena; NOTTINGHAM, Mara Carvalho; FERREIRA NETO, José Ambrósio; ESTRELA, Lílian Mércia Benevenuto; SANTOS, Bruna de Vita Silva; FIGUEREDO, Natália Aragão de. A diversidade produtiva em Reservas Extrativistas na Amazônia: entre a invisibilidade e a multifuncionalidade. Desenvolv. Meio Ambiente, v. 48, Edição especial: 30 Anos do Legado de Chico Mendes, p. 164-183. 2018. Disponível em: <https://revistas.ufpr.br/made/article/view/58805>. Acesso em 13 nov. 2021.

TONUCCI FILHO, João Bosco Moura. Além do Estado e do Capital: notas sobre três abordagens críticas do Comum. Crítica Marxista, n.49, p.153-173, 2019. Disponível em: $<$ https://www.ifch.unicamp.br/criticamarxista/sumario.php?id_revista=66\&numero_revista=4 9>. Acesso em 16 nov. 2021. 


\section{Artigo recebido em: dezembro/2021}

Artigo aceito em: fevereiro/2022 